\title{
Patterns and models of flowering of some Campanulaceae Juss. species
}

\author{
E. Fomin ${ }^{1 *}$, T. Fomina ${ }^{2}$ \\ ${ }^{1}$ Institute of Cytology and Genetics SB RAS, Novosibirsk, Russia \\ ${ }^{2}$ Central Siberian Botanical Garden SB RAS, Novosibirsk, Russia \\ *e-mail:fomin@bionet.nsc.ru
}

Key words: flowering models, Campanulaceae

Motivation and Aim: Flowering is the most important event in the seasonal cycle of plant development, the realization of which largely determines reproductive success. This process can be studied at different levels of organization - organ, individual, population, phytocenotic, each of which is characterized by its own set of tasks and research methods. There are a number of prognostic models of phenological development, including flowering, for various taxonomic and biomorphological groups of plants $[1,2]$. However, most of the existing models describe the flowering process at the population level, while insufficient attention is paid to modeling individual flowering. The purpose of this work is to study the flowering patterns of a number of species of the Campanulaceae family and to construct a computer model suitable for analysis and prediction of their decorativeness.

Methods and Algorithms: The subjects of the study were representatives of the family Campanulaceae Juss. and a large-bellied large-billed Platycodon grandiflorus (Jacq.) A. DC. from the collection of ornamental plants of the natural flora of the Central Siberian Botanical Garden of the SB RAS (Novosibirsk). The investigated species are characterized by a summer-brightening phenorhythmotype, with summer flowering dates for Campanula (late June to mid-July) and late-summer for Platycodon grandiflorus (second half of July). Phenological observations were carried out on shoots of each species during the entire flowering period. Observation data were statistically processed, repeatability in shoot structure and stable relationships between the position of flowers on them and the time of their disclosure were revealed.

Results: A stochastic structural dynamic model of flowering of shoots was constructed and implemented in the form of a computer program. It allows to predict the structure of the shoot and the phase of development of its generative organs for any date from the beginning of flowering. Three different flowering patterns were found: unimodular (C. bononiensis), bimodular (C. sarmatica) and a bimodular one with a strongly protracted phase of the beginning of flowering (P. grandiflorus). The reasons for the formation of these patterns were analyzed.

\section{References}

1. Normand F., Habib R., Chadoeuf J. (2002) A stochastic flowering model describing an asynchronically flowering set of trees. Annals Botany. 90:405-415.

2. Erwin J. (2007) Factors affecting flowering in ornamental plants. In: Flower breeding and genetics (issues, challenges and opportunities for the 21 st century). Ed. N.O. Anderson. Minnesota. 7-48. 